\title{
Uma questão de essência: classificadores para o corpo \\ humano em Apinayé
}

\author{
A matter of essence: human body classifiers in Apinaye \\ Laísa Fernandes TOSSIN* \\ Universidade Estadual de Campinas (Unicamp)
}

\begin{abstract}
RESUMO: Este trabalho apresenta uma análise morfofonológica associada a uma descrição semântica de termos em Apinayé relacionados ao corpo humano, elaborando as possíveis implicações entre o pensamento Apinayé e sua noção de pessoa. Também apresenta explicações sobre a relação entre o ato de nomear o mundo e a eleição de elementos formadores da realidade, do humano e da cosmologia. Mostra alguns termos de Apinayé relacionados ao corpo humano e desenha suas relações com os elementos culturais constitutivos, tais como: centro da vila, leite materno e sangue menstrual.
\end{abstract}

PALAVRAS-CHAVE: Linguística. Pragmática. Relações semânticas.

ABSTRACT: This paper presents a morphophonological analysis related to a semantic description of terms in Apinayé related to human body, constructing all possible implications between the Apinayé thought and their notion of person. It also presents some possible explanations of the relation between the act of naming the world and the election of formative elements of reality, of human e of cosmology. It shows some terms of Apinayé related to human body and draws its relations with constitutive cultural elements such as: centre of the village, mother's milk and menstrual blood.

KEYWORDS: Linguistics. Pragmática. Semantic relations.

\section{Introdução}

Sapir (1980) nos iluminou com sua suposição de que língua e cultura partilhariam a mesma origem: o convívio social humano. Ainda, nos fez considerar que a linguagem não se dá a partir do pensamento, mas sim o oposto, da linguagem surge a possibilidade do pensar, e do pensamento teríamos, então, a matéria conceitual necessária para o desdobrar-se da cultura. A linguagem seria, de fato, o próprio fundamento da cultura. (JAKOBSON, 2003) Então, nesta cadeia lógica, teríamos uma intrincada relação entre língua e cultura capaz de nos revelar, em parte, aspectos de uma imbricados na outra, e vice-versa.

\footnotetext{
* Doutoranda em Linguística pela Universidade Estadual de Campinas.
} 
O entendimento que o homem constrói de si mesmo, a compreensão de ser/estar no mundo, a decodificação da experiência e sua transmissão às gerações sucedâneas, todos estes processos expressos pela linguagem serviriam de farol a nos clarear o caminho da busca pelo tempo perdido, aquele momento primeiro em que se criou a representação primordial da experiência da vida. (DELANCEY, 2008; BENVENISTE, 1989)

Por representação entende-se um quê de ficção, certo aspecto colorido de criatividade e múltiplas escolhas para designar e entender o mundo seja em sua manifestação concreta seja no inatingível. Assim, podemos entender as escolhas fonológicas de uma língua como fruto de mera arbitrariedade, mas sua manutenção e propagação ao longo da história teceram redes de significação cultural, dando-lhes sustentabilidade orgânica e coerência semântica que conduziram a experiência e trouxeram sentido aos que vieram depois. (DELANCEY, 2008; BENVENISTE, 1989)

É justamente por meio das formas propagadas ao longo da história da língua Apinayé que pretendo traçar as possíveis relações entre padrões linguísticos e aspectos culturais relevantes, a iniciar pela denominação do corpo e de coisas e processos que o tornam humano. É notório que, em várias sociedades indígenas, o corpo do recémnascido precisa tornar-se humano por meio de rituais que lhe agreguem as substâncias necessárias para que se materialize o humano naquele corpo. (SANTOS-GRANERO, 2009; HUGH-JONES, 2009; CAYÓN, 2013)

Ainda é necessário compreender, sob o prisma da composição do mundo, as diferentes CULTURAS existentes, pois os elementos formadores do cosmos não são os mesmos para todas elas. Alguns trabalhos recentes em antropologia ${ }^{1}$ começaram a levantar a existência de substâncias formadoras do universo compreendido por determinadas culturas, portanto, minha suposição é que traços linguísticos poderiam ser identificados nas relações semânticas criadas por estas substâncias. É claro, estou aqui supondo que nos apegamos com força à forma e a seu significado, deixando pouco espaço para a incorporação de novidades, porém não ignoro a existência de mudanças linguísticas nem as importações de termos de outras línguas com as quais temos contato.

\footnotetext{
${ }^{1}$ Jonathan Hill (2002) escreveu um artigo no qual demonstra como os classificadores nominais de número servem também para colocar tipos de pessoas, animais e coisas em seus devidos lugares existenciais.
} 
Posso apontar, como exemplo, a construção que nossa cultura e nossa língua fizeram do nosso corpo e reconfigurar um provável caminho histórico de como o entendemos. Assim, o corpo, este corpo formado por concepções gregas, iniciou seu processo com o phúsis, que, para os princípios pré-socráticos era a matéria de fundamento eterno de todas as coisas, desenrolou-se em phúsis $>$ fito=fisio, referente ao orgânico, à regulação do funcionamento do corpo e da natureza. Para os gregos, porém, a palavra corpo não se referia, senão, ao cadáver, inerte, sem vida. Um corpo era então, démas ou anima em latim, origem de alma, espírito. Um corpo com vida seria uma alma. Em algum momento da história da ciência, o cadáver passou a ser sinônimo de vida, e a vida deixou de ser relevante para que o mecanismo (corpo/órgãos/tecidos) fosse o principal.

Esta relação se estende para os domínios da natureza, já que fito, sinônimo de fisio, se refere à regulação do sistema biótico vegetal: a natureza. Do latim, natureza e nascer partilham o mesmo radical, revelando a intimidade de homem e natureza colocando-os em pé de igualdade com relação a sua forma de surgir no mundo.

Além disso, phúsis, também, derivou-se em phýsa, ar, um dos elementos que compõem o mundo pré-socrático, sendo de fundamental importância para a determinação da vida de um corpo, fortemente relacionado à primeira respiração do recém-nascido e ao último alento do moribundo. E assim, fechamos o círculo se voltarmos aos pré-socráticos e reavivarmos a discussão a respeito da essência do homem; o ser. O que me parece interessante salientar é que a matéria que compõe o cosmos e o corpo tem tantas variações quantas são as línguas no mundo. Para algumas culturas, pode ser o tabaco, a pupunha, a ayahuasca ou a coca; para outras: ar, água, terra e fogo.

Antes de elaborar qualquer análise, é importante apontar algumas questões gerais de como a etnologia contemporânea tem tratado a noção de pessoa. Atualmente, há um consenso sobre o fato de que, nas sociedades amazônicas, a pessoa é concebida como um ser processual e divisível (LAGROU, 2007), pelo qual circulam partes de outras pessoas para produzir novos seres, seja pelo consumo constante das mesmas substâncias dentro de um grupo doméstico (OVERIG; PASSES, 2000), seja pela troca de fluidos corporais e através das memórias dos cuidados recebidos na infância (GOW, 1991) ou pela incorporação de nome e almas baseados em um esquema relacional de 
predação ontológica (VIVEIROS DE CASTRO, 1996. Santos-Granero (2009) chama a atenção para a importância dos objetos na construção da pessoa dentro das cosmologias ameríndias, que requerem sempre a desconstrução e reconstrução de corpos, compostos por partes de objetos, artefatos, plantas e animais, dos quais a anatomia humana, assim como a de outras formas de vida, se constitui.

Por incluir espíritos, plantas e animais dotados de alma, de consciência reflexiva e de intencionalidade (DESCOLA, 1998), a categoria corpo carrega o entendimento de que cada corpo é a singularização de afetos, inclinações e capacidades particulares de sua espécie, assim, ao estar imbuído de agencialidade, este corpo definirá como o mundo será percebido. (VIVEIROS DE CASTRO, 1996)

Portanto, entender que as partes do corpo humano são dotadas de agentividade e intencionalidade, lhes atribui um caráter muito mais agentivo, o que, ao procurarmos estabelecer relações semânticas precisam ser consideradas.

Assim, a complexidade de prefixos e classificadores relativos às partes do corpo pode ser iluminada pela compreensão de que, a exemplo da cosmologia Pano, cada parte do corpo pode possuir uma alma própria, com agencialidade e intencionalidade, e relações com outros seres, inclusive os seres primordiais, os lugares e o tempo.

Para o estabelecimento das relações semânticas possíveis em línguas ameríndias, é inevitável construir um elo entre as informações etnográficas e as descrições linguísticas. Isso possibilitaria iluminar questões como categorias gramaticais sob a perspectiva indígena, rompendo, em alguns casos, com as estruturas ocidentais convencionadas para a descrição e o estudo das línguas.

\section{A construção do corpo no universo indígena Apinayé}

Os Apinayé têm sido antropologicamente estudados com regularidade desde o século passado. Há os trabalhos de DaMatta (1976) e Giraldin (2000, 2001), além, é claro, do clássico Os Apinayé, de Nimuendajú (1956). Os estudos linguísticos estão fortemente ligados aos missionários, em especial, a Wisemann (1986), e também a Ham (1961, 1979), Waller (1974), e Koopman (1979), e aos linguistas Callow (1962), Salanova (2001), Oliveira (2003, 2005), Albuquerque (2007) e Coffman (2008). 
Meu maior interesse em pesquisar esta língua já tão descrita e analisada é justamente buscar os pontos de coesão entre a língua e a cultura produzida pelos Apinayé, aproveitando-me das detalhadas descrições existentes para ampliar seu escopo semântico. Em especial, as relações entre o verbo ka, 'ser'; e suas ocorrências como morfema ou radical.

Diferentemente do que vem sendo dito sobre este formativo' ' $k a$ ', entendo-o como um morfema que desempenha função de classificador, formando uma categoria de verbos iniciados por ele, com relação semântica entre si e, portanto, imagino se haveria alguma relação entre este formativo ' $k a$ ' e alguma substância formadora do mundo, tendo em vista que está presente também em palavras que especificam determinados graus de parentesco, como (DAMATTA, 1976):

$\begin{array}{ll}\text { akatxoiti } & \text { 'filha' } \\ \text { akantêre } & \text { 'filho' }\end{array}$

Existem outros morfemas em Apinayé que formam classes de verbos, tais como: ku e pia. Desde já apresento estes elementos como sendo de relevante interesse para este artigo, não apenas por integrarem a língua Apinayé, mas por ser $k u$ uma mudança diacrônica de $k a$, que também é pronome de $2^{\mathrm{a}}$ pessoa singular. E pia forma uma classe de verbos que dizem respeito ao nascimento e aos eventos pós-parto, tais como a amamentação e a reclusão (OLIVEIRA, 2003). Entretanto, não me deterei, neste momento, para analisá-los.

Além das relações semânticas e morfológicas entre estes termos, também pretendo uma reanálise das glosas e traduções livres apresentadas para os dados da língua, pois, parece-me que as traduções realizadas não equivalem semanticamente aos termos que se pretende traduzir. A questão da tradução em línguas indígenas sempre demonstrou ser um desafio para qualquer linguista devido ao viés cultural ao qual estamos atados e com o qual é impossível romper, pois, ao nos propormos a fazer uma tradução esperamos encontrar elos entre uma língua e outra que tornem possível a

\footnotetext{
2 Oliveira (2005) considera que estes morfes que aparecem em classes de palavras específicas não fazem parte de um sistema morfologicamente produtivo, são fósseis morfológicos que servem apenas para classificar palavras em classes, são vazios semanticamente ou possuem significados elusivos, por isso chama-os de 'formativos' e não de 'morfemas'.
} 
compreensão para os falantes de nossa língua (BENVENISTE, 1989). Como minha proposta é, primeiro, a imersão cultural no universo Apinayé, para posterior tradução, entendo que algumas das traduções realizadas apresentam equívocos que, por sua vez, geram enganos fonológicos.

Um exemplo é a palavra ke, traduzida como 'corpo, pele, peito', que pode ser um alofone de $k a$ ou simplesmente a flutuação da vocalização, em vez de um item lexical diferente, como é possível visualizar em kator-txô 'mãe', que literalmente significa 'de onde sai um corpo' (DAMATTA, 1976).

Assim também, o par opositor [kr $\Lambda$ ] [krã] $(\mathrm{Ham}, 1961)$ foi rechaçado na tese de Cristhiane de Oliveira (2005), que argumenta a impossibilidade de comprovar em campo a existência da vogal nasal [ã] em Apinayé, portanto, não a inclui em seu quadro de fonemas vogais da língua. No entanto, ela estabelece a existência de duas vogais distintas para o mesmo par opositor: [kr $\Lambda$ ] e [kra]. Este par krá/krã ou krá/kra, comumente usado como par opositor para testar a presença dos fonemas das vogais aberta e nasal na língua, é, portanto, sempre tratado como se representasse dois itens lexicais diferentes, sendo krá 'filho-criança' e krã/kra 'cabeça'. Porém, as concepções expressas por estas palavras representam algo bem maior e mais extenso que a tradução para o português pode abranger.

Para Ham (1961), krá é a palavra usada para referir-se aos filhos ou às crianças, em geral, e krã é 'cabeça', constituindo-se assim a diferença lexical necessária para comprovar a existência de ambas as vogais. Assim como para Ham (1961), para Oliveira (2005), krá refere-se a filho ou criança, mas 'cabeça' é kra. Em ambos os casos, a distinção lexical é definida pela existência de oposição fonológica entre estas vogais.

Entretanto, poderíamos supor aqui, a existência de um categorizador da forma "redondo", supostamente relacionado à vogal nasal, como ocorre em Kaingang (D’ANGELIS, 2002). Porém, ao fazer uma pequena lista de palavras relacionadas a termos de parentesco, pude perceber que o termo $k r a \tilde{a}$ ou $k r a$, embora traduzido literalmente como 'cabeça', aparece diretamente relacionado à criança.

No sistema de nomeação Apinayé, como citado por DaMatta (1976), os genitores escolhem, entre seus amigos formais (pakrã/krã-geti), aquele que dará nomes 
à criança. Após estabelecida a formalidade, o nomeador e o nomeado passam a se tratar pelos seguintes termos (DAMATTA, 1976):

id-krã-tum 'nomeador' (literalmente 'minha cabeça velha')

id-krã-dúw 'nomeado' (literalmente 'minha cabeça nova').

Embora, literalmente a referência seja feita à cabeça, semanticamente, remete à criança/filho. Se visualizarmos que, ao nascer, a primeira parte do corpo humano que desponta no canal vaginal é a cabeça teríamos uma unidade semântica que se estende de krá/kra alcançando krã. A cabeça é, das partes do corpo, a mais significativa para os Apinayé, visto o cuidado e a relevância do corte de cabelo e dos adornos cerimoniais identificadores de cada metade amarrados sobre o sulco criado pelo corte de cabelo (DAMATTA, 1976). Além do zelo no trato do cabelo, o corte em muito se assemelha ao formato das casas que, em um sistema uroxilocal, estão relacionadas à vagina da mãe. O verbo usado para dizer 'eu saio', referindo-se ao ato de sair fisicamente da casa, é idkatoro, em que id_é relativo à primeira pessoa, remetendo-nos a kator-txô 'mãe'. Talvez, krã sequer signifique 'cabeça', mas sim conduza ao entendimento mais amplo da compreensão de corpo e de pessoa Apinayé, assim como do mundo que os cerca.

O que se propõe aqui é tomar como referência a noção de pessoa manifestada na peculiaridade de cada grupo humano ao nomear e classificar o mundo ao seu redor. Alguns verbos intransitivos em apinajé possuem uma marcação diferenciada em seus pronomes pessoais, mesmo aqueles verbos que exprimem ação voluntária como é o caso de 'sair' apoj (plural) e kató (singular) ou 'correr' prõt, que recebem pronomes da série II $\left(i_{-} \mathrm{C}\right)$, equivalentes à marcação de objeto e não à subjetiva. Alguns sistemas de marcação de caso refletem um tipo de organização de marcação de caso motivada semântica e gramaticalmente (TOSSIN, 2009).

Tradicionalmente a análise dos verbos kató e apoj se dá no âmbito da diferença ativo/estativo, mas proponho uma perspectiva diferente de entendimento a respeito das escolhas gramaticais, compreendendo o papel que a cultura e a pragmática exercem sobre o falante. Assim, os verbos 'sair de casa', 'nascer', e os nomes 'cabeça' e 'criança/pessoa' estão profundamente relacionados (TOSSIN, 2009). DRYER (1997) 
nos explica que os novos falantes aprendem estas palavras como unidades individuais que não apenas descrevem entidades, propriedades ou eventos, mas sim, os nomeiam.

$\mathrm{Na}$ categoria de verbos com o formativo $k a$, conforme descrita por Oliveira (2005), existem verbos transitivos e descritivos referentes ao contato físico ou à manipulação, aos cabelos, a mudanças de estado, ao estado líquido, a tudo que possui formato esférico, redondo como a cabeça. Para a autora, não há relação semântica entre os verbos desta categoria, embora não haja idiossincrasia morfológica entre eles.

$\begin{array}{ll}\text { ka } & \text { 'corpo/ser' } \\ \text { kagró } & \text { 'ser (tornar-se) quente/ter febre' } \\ \text { ka'i } & \text { 'ser (tornar-se) fino' } \\ \text { karor } & \text { 'ser louro' } \\ \text { kago } & \text { 'suco/espremer o suco' } \\ \text { kabro } & \text { 'sangue/menstruar' } \\ \text { karot } & \text { 'trabalho de parto' } \\ \text { ka kago } & \text { 'leite materno' }\end{array}$

Para mim, na longa lista de verbos da categoria $k a$, aqui representada por poucos exemplos, a relação mais relevante é com o corpo, e com seus elementos formadores mais importantes: o líquido, os cabelos e a cabeça, pois na concepção Apinayé da composição do corpo, estão o leite materno, o sangue da mãe e o esperma.

\section{Considerações Finais}

Estes dados me fazem refletir sobre o cuidado no estabelecimento dos pares opositores $[\mathrm{kr} \Lambda][\mathrm{krã}] /[\mathrm{kra}]$ para o teste de existência das vogais $[\Lambda] /[\tilde{a}]$, pois estabelecer a distinção semântica entre termos lexicais tão semelhantes requer conhecimento a respeito da noção de pessoa, de pertencimento e de humanidade dos Apinayé. Visto que a vogal nasal [ã] pode não existir, ou não mais existir na fala deste grupo, permanece a distinção entre $[\Lambda ;$ a], porém a distinção lexical atribuída a krá e kra é passível de questionamento.

Além disso, temos outra perspectiva para krá que poderia receber a tradução 
'pessoa', podendo ser encontrada nas autodenominações dos povos Timbira, como, por exemplo, apãniekrá.

Como os demais grupos Jê, os Apinayé dividem-se em diversas metades cerimoniais além das metades cosmológicas conhecidas pelos nomes Kolti - Kolre, que representam o Sol e a Lua. O Sol (Kolti), o mais velho, e a Lua (Kolre), o mais novo, constituem-se nas categorias mais amplas para classificar o mundo Apinayé, porém recebem outros nomes cerimoniais, usados em festas e que determinam o caráter dos membros que fazem parte destas metades, assim, Kolti, o irmão mais velho, é mais sisudo e recebe o nome de Ipôgnotxóine e Kolre, o irmão mais novo, Krénotxóine, mais alegre e sorridente. Durante as festas, a metade Krénotxóine canta alto, dança, faz piadas com os membros da outra metade e rouba pertences de dentro das casas, enquanto os Ipôgnotxóine apenas observam quietos e sérios (DAMATTA, 1976; GIRALDIN, 2000, 2001). Oliveira (2005) trouxe em seu trabalho uma tradução diferente para estas metades cerimoniais, como apresentadas abaixo:

\author{
Ipôgnotxóine \\ 'pessoa do centro' \\ /ipok.nh-õ.ce'wnh/ \\ centro.RP-GEN.NMLZ
Krénotxóine 'pessoa que canta e dança'
/grér.nh-õ.ce'wnh/
dance/sing-NF.RP-GEN.NMLZ

As qualidades de ambas as metades estão, de certa forma, morfologicamente expressas nos nomes cerimoniais, se entendermos que $k r e^{3}$ pode ser uma forma equivalente de krá, então, entenderíamos que o comportamento jocoso da metade Krénotxóine é próprio das ou permitido às crianças, e teríamos uma unidade semântica e morfológica que se estende alcançando kra. Além disso, kré recebe a tradução 'pessoa' e podemos encontrá-la também nas denominações dos povos como, por exemplo,

\footnotetext{
3 Um estudo realizado por Oliveira e Ribeiro (2005) revela a correspondência fonológica da vogal central média $/ \Lambda /$ à vogal frontal média-baixa /\&/ respectivamente entre Jê do Norte e Jê Central.
} 
mebengokré e apãniekrá, ou seja, a noção de pessoa destes grupos está relacionada a este morfema.

Talvez, a universalidade das categorias gramaticais não exista da forma com que gostaríamos de encontrá-la, com extratos comuns nos quais basta enquadrar as palavras encontradas em línguas diferentes ao redor do mundo e traduzi-las da maneira mais aproximada possível. Proponho que se perceba a peculiaridade de cada grupo humano ao nomear e classificar o mundo ao seu redor. Se o mundo Apinayé é dividido em metades, às quais tudo deve pertencer, então, é possível que também as palavras tenham sua forma de pertencer a cada metade.

\section{REFERÊNCIAS}

ALBUQUERQUE, Francisco Edviges. Contribuição da fonologia ao processo de educação indígena Apinayé. Tese (Doutorado em Estudos Linguísticos)-Instituto de Letras, Universidade Federal Fluminense. Niterói, 2007. 255 f.

BENVENISTE, Émile. Problemas de Lingüística Geral II. Campinas: Pontes, 1989.

CALLOW, John. The Apinayé language: phonology and grammar. Tese. (Doutorado)University of London. Londres, 1962.

CAYÓN, Luis. Pienso, luego creo: La teoria makuna del mundo. Bogotá: Instituto Colombiano de Antropologia, 2013.

COFFMAN, Ian. Antihomorganicity. In: Apinayé and Hayu: evidence for closure duration as a phonotactic variable. Tese. University of California. Berckley, 2008.

DaMATTA, Roberto. Um mundo dividido: a estrutura social Apinayé. Petrópolis: Vozes, 1976. Coleção Antropologia, 10.

D'ANGELIS, Wilmar.Gênero em Kaingang?. In: SANTOS, Ludoviko; PONTES, Ismael (Orgs.). Línguas Jê: estudos vários. Londrina: Eduel, 2002. p. 215-242.

De LANCEY, Scott. Lectures on functionalism syntax. EUA: Universidade de Oregon,. Disponível em: 〈http://www.uoregon.edu/ delancey/prohp.html\#T>. Acesso em: 21 out. 2008.

DESCOLA, P. Estrutura ou sentimento: a relação com o animal na Amazônia. Mana, Rio de Janeiro, v.4, n.1, p. 23-45, 1998.

DRYER, Matthew S. Are Grammatical Relations Universal?. In: BYBEE, Joan; HAIMAN, John; THOMPSON, Sandra (Eds.). Essays on Language Function and Language Type: Dedicated to T. Givon. Amsterdam: J. Benjamins, 1997. p. 115-143.

GIRALDIN, O. Axpên pyrák: história, cosmologia, onomástica e amizade formal apinaje. Tese. (Departamento de Antropologia, Instituto de Filosofia e Ciências Humanas da Unicamp). Campinas, 2000. 
GOW, P. Of mixed blood: kinship and history in Peruvian Amazon. Oxford: Clarendon, 1991.

HAM, P. Apinayé Grammar: preliminary version. Anápolis: Summer Institute of Linguistics, 1961.

HAM, P.; KOOPMAN, L.; WALlER, H. Aspectos da Língua Apinayé. Cuiabá: Summer Institute of Linguistics, 1979.

HILL, Jonathan; SANTOS-GRANERO, Fernando. Introduction to a comparative Arawakan histories: rethinking language family and culture area in amazonia. Chicago: University of Illinois Press, 2002.

HUGH-JONES, Stephen. The fabricated body: objects and ancestors in northwest Amazônia. In: SANTOS-GRANERO, F. (Org.) The occult life of things: native amazonian theories of materiality and personhood. Tucson: The University of Texas Press, 2009.

JAKOBSON, R. Linguística e Comunicação. 19. ed. São Paulo: Cultrix, 2003.

LAGROU, E. A fluidez da forma: arte, alteridade e agencia em uma sociedade amazônica (Kaxinawá, Acre). Rio de Janeiro: Topbooks, 2007.

NIMUENDAJÚ, Kurt. Os Apinayé. Boletim do Museu Paraense Emilio Goeldi. Tomo XII. Belém: Instituto Nacional de Pesquisas da Amazônia, 1956.

OLIVEIRA, Christiane. Lexical categories and the status of Descriptives in Apinajé. International Journal of American Linguistics, Chicago, v. 69, n. 3, p. 243-274, 2003.

OLIVEIRA, Christiane. The Language of the Apinajé People of Central Brazil. Tese (Doutorado)-Departamento de Linguística da Universidade de Oregon. Oregon, , 2005.

OLIVEIRA, Christiana; RIBEIRO, Eduardo. Vowel shift in Central Jê. In: INTERNATIONAL CONFERENCE ON HISTORICAL LINGUISTICS, 17. Anais...Estados Unidos: University of Wisconsin, 2005.

OVERIG, J.; PASSES, A. Conviviality and the opening up of Amazonian anthropology. In: OVERIG, J.; PASSES, A. The anthropology of Love and anger: the aesthetics of conviviality in the native Amazônia. Londres. Nova York: Routledge, 2000. p. 1-30.

SAPIR, E. A Linguagem.. Perspectiva: São Paulo, 1980. Coleção Estudos.

SANTOS-GRANERO, F. Amerindian constructional views of the world. In: SANTOSGRANERO, F. The occult life of things: native amazonian theories of materiality and personhood. Tucson: The University of Arizona Press, 2009. p. 1-29

SALANOVA, Andrés Pablo. A nasalidade em Mebengokré e Apinayé: o limite do vozeamento soante. Dissertação (Mestrado) - Programa de Pós-Graduação em LinguísticaUnicamp, Campinas, 2001.

TOSSIN, Laísa. Intransitividade cindida em Apinajé. Dissertação (Mestrado)- Programa de Pós-graduação em Linguística, Universidade de Brasília. Brasília, 2009. 116 p.

VIVEIROS DE CASTRO, E. Os pronomes cosmológicos e o perspectivismo ameríndio". Mana, n. 2, v.2, p.115-144, 1996. 
WIESEMANN, U. The pronoun systems of some Jê and Macro-Jê languages. In: WIESEMANN, U. (Ed.). Pronominal systems. Tübingen: Gunther Narr Verlag, 1986. p. 359-380.

WALLER, H. E. A Conjunção Nhũm na Narrativa Apinajé. Brasília: Summer Institute of Linguistics, 1974. 